\title{
Prevalence of functional constipation and constipation-predominant irritable bowel syndrome in Indian patients with constipation
}

\author{
Ramesh Rooprai $^{1}$, Naresh Bhat ${ }^{2}$, Rajesh Sainani ${ }^{3}$, Mayur M. Mayabhate ${ }^{4 *}$
}

${ }^{1}$ Rai Specialty Care Centre, Shyam Nagar, Jaipur, Rajasthan 302019, India

${ }^{2}$ Columbia Asia Hospital, Kirloskar Business Park, Vinayakanagar, Bengaluru, Karnataka 560024, India

${ }^{3}$ Sainani Medicare Clinic, 401,

Doctor House, Haji Ali,

Mumbai 400034, India

${ }^{4}$ Abbott India Limited, 271, Business Park, $7^{\text {th }}$ floor, Model Industrial Colony, Off Aarey Road, Goregoan (E), Mumbai, Maharashtra 400063, India

Received: 27 December 2016

Revised: 02 January 2017

Accepted: 03 January 2017

*Correspondence to:

Dr. Mayur M. Mayabhate,

Email:

mayur.mayabhate@abbott.com

Copyright: (C) the author(s), publisher and licensee Medip Academy. This is an openaccess article distributed under the terms of the Creative Commons Attribution NonCommercial License, which permits unrestricted noncommercial use, distribution, and reproduction in any medium, provided the original work is properly cited.

\begin{abstract}
Background: Evaluate prevalence of functional constipation (FC) and irritable bowel syndrome-constipation (IBS-C) in Indian constipated patients and assess their demographic/socio-economic/clinical characteristics.

Methods: Patients ( $\geq 18$ years) who visited their general physician with symptoms of constipation (Rome III criteria for FC or IBS-C as per physician assessment) and willing to participate were enrolled in this prospective, clinicalepidemiological study. Demographic, socioeconomic status, lifestyle and dietary habits, comorbid conditions, treatment history, concomitant medications, stool form (Bristol stool form scale), severity of constipation (constipation scoring system [CSS]), constipation-related symptoms (patient assessment of constipation symptoms [PAC-SYM]) and quality of life (patient assessment of constipation-quality of life questionnaire [PAC-QoL]) were recorded.

Results: Out of 925 constipated patients, $75.6 \%$ were diagnosed with FC against $24.4 \%$ with IBS-C (P $<0.0001)$. Patients of both subtypes had high average scores of PAC-SYM (FC: $27.1 \pm 6$; IBS-C: $30.1 \pm 4.9)$ and CSS (FC: $8.4 \pm 3.1$; IBS-C: $11.2 \pm 3$ ), leading to high PAC-QoL score (FC: $38.1 \pm 16.8$; IBS-C: $42.2 \pm 13.6)$. Hypertension $(16 \%)$ and diabetes $(10 \%)$ in patients with FC while acid peptic disorders $(21.7 \%)$ amongst IBS-C patients were the most common comorbid conditions observed. Laxatives were the most common medication used; osmotic (32.6\% versus $40.7 \%)$ and bulk laxatives $(22.8 \%$ versus $37.4 \%$ ) were the commonest laxatives. However, about $1 / 5$ th patients of FC were using home remedies.

Conclusions: There was a higher prevalence of FC over IBS-C in Indian constipated patients; both subtypes had high frequency and severity of constipation-related symptoms and poor QoL.
\end{abstract}

Keywords: Constipation scoring system, Co-morbid conditions, Laxatives, PAC-SYM, PAC-QoL

\section{INTRODUCTION}

The word "constipation" has varied meanings for different individuals. Although medical personnel define constipation as <3 bowel movements per week, patients often equate constipation with stool consistency, feelings of incomplete emptying, straining, and urge for defecation. Risk factors for constipation include older age, physical inactivity, low caloric intake, low-fiber diet, low income, low educational level, various systemic and gastrointestinal (GI) disorders as well as medications. ${ }^{1}$ It has been reported to be more common in women, nonwhites and elderly people aged $>65$ years. The prevalence of constipation ranges from $8.75 \%$ in Asia Pacific to $27 \%$ in the Western countries. ${ }^{2}$ 
Functional constipation (FC) and irritable bowel syndrome (IBS) are among the most common functional GI disorders globally and significantly impacts the patient's quality of life (QoL), irrespective of their culture or nationality. ${ }^{3,4}$ The worldwide prevalence of FC and IBS-constipation (IBS-C) ranges from 5\% to $25 \%$ and $10 \%$ to $20 \%$, respectively. ${ }^{5,6}$

The assessment of constipation remains a challenge due to various reasons like different criteria used for evaluation, varying diagnostic tools and the subjective nature of the patient's perception of what they consider as constipation. Hence, systematic evaluations are better rather than relying on patient to volunteer information related to their specific symptoms for better management of these patients. ${ }^{2,7,8}$

Little is known about the epidemiology and clinical subtypes of constipation in the general Indian constipated population. Hence, the present study was conducted to evaluate the prevalence of FC and IBS-C in Indian constipated patients along with assessment of their demographic, socioeconomic, lifestyle and dietary habits, usage of constipation-related medications and comorbid conditions.

\section{METHODS}

\section{Study site details}

A non-interventional, prospective, cross-sectional, clinicepidemiological, single visit study was conducted across 20 centers in India, 3 centers each at Ahmedabad, Kolkata, Mumbai and Jaipur and 2 centers each at Bangalore Chennai, Delhi and Pune, from November 2014 to March 2015. The study was conducted in accordance with the Declaration of Helsinki, International Conference on Harmonization of Good Clinical Practice guidelines, Indian Council of Medical Research, Indian Good Clinical Practice guidelines and the approved protocol. The study protocol was approved by the respective institutional ethics committee in each center.

\section{Study inclusion and exclusion criteria}

Consecutive patients of age $\geq 18$ years who visited their general physician with symptoms of constipation (fulfilling Rome III criteria for FC or IBS-C as per physician assessment) and willing to sign the patient authorization form were invited to participate in the study. Patients who had intestinal obstruction, acute abdomen (sudden, severe abdominal pain of unclear etiology), any disease with the potential to precipitate intestinal obstruction, pregnant or lactating females were excluded from the study. Since the objective of the study was to determine the prevalence of FC and IBS-C among the patients of constipation, patients presenting with constipation apart from FC and IBS-C (not fulfilling Rome III criteria) were not considered.

\section{Study variables}

The patients were asked questions related to their demographics, socioeconomic status, lifestyle, dietary habits, frequency and severity of constipation symptoms, QoL, treatment and medical history, concomitant medications, co-morbid conditions and medical and surgical procedures. Dietary details were captured on the basis of patient recall of the past 2 weeks. These data included assessment of consumption of vegetables, fruits, proteins (in grams each) and water (in litres) per day. The socioeconomic status, stool form, frequency of symptoms, severity of constipation, QoL, was assessed by Kuppuswamy socioeconomic status scale, Bristol Stool form Scale (BSFS), Patient Assessment of Constipation symptoms (PAC-SYM), Constipation Scoring System (CSS) and Patient Assessment of Constipation-Quality of Life questionnaire (PAC-QoL) respectively. Since the predominant population for this study was urban, the Kuppuswamy scale (latest version 2014) was used for data on the socioeconomic status based on occupation, education and family income. These questionnaires were administered to the patients by the investigator or the trained designee who enabled to capture information with greater accuracy and confidentiality (Standard English versions were used). Patient data were collected and sent for analyses.

\section{Statistical analyses}

There was no pre-determined statistical hypothesis tested. Assuming that the prevalence rates of FC and IBS-C were $31 \%$ and $14 \%$, respectively, among Indian adults suffering from constipation, enrolling 920 evaluable patients would have enabled to calculate a $95 \%$ confidence interval (CI) with a precision of at least $3 \%$ around the estimated prevalence rates of both subtypes of constipation. ${ }^{9,10}$ Descriptive statistics (generated using Statistical Analysis System ${ }^{\circledR}$ version 9.3 software) was used to summarize the variables; the continuous variables were summarized by counts, mean \pm standard deviation, median, range and the categorical variables were summarized by frequency and percentages. All the statistical testing was compared with two-sided significance level $\alpha=0.05$. The $P$ value for the continuous and categorical data was calculated using 2-sample t-test and chi-square test, respectively.

\section{RESULTS}

\section{Patient demographics}

A total of 925 patients with constipation were screened and enrolled in the study after meeting the eligibility criteria and signing the PAF (Figure 1). Of these patients, a statistically significant higher proportion of patients were diagnosed with FC as compared to IBS-C $(75.6 \%$ versus $24.4 \% ; P<0.0001)$. The average age of patients with FC was statistically significant higher than patients with IBS-C $(46.8 \pm 16.9$ years versus $43.8 \pm 16.3$ years; 
$P=0.0199)$. However, by age, there was no statistically significant difference between the constipation subtypes. Gender and residence distribution amongst constipation subtypes was found to be statistically significant $(P$ $<0.0001)$. In both subtypes, males predominated females (FC: $63.1 \%$ versus $36.9 \%$ patients; IBS-C: $65.5 \%$ versus $34.5 \%$ patients) and urban population predominated rural population (FC: $71.5 \%$ versus $28.5 \%$ patients; IBS-C: $62.0 \%$ versus $38.1 \%$ patients).

\section{Socioeconomic characteristics}

There was no statistically significant difference in the total mean score (education + occupation + family income/month) between the subtypes $(P=0.3875)$. Patients with IBS-C had statistically significant higher scores of education $(P=0.0026)$ and occupation $(P=$ 0.0031) and patients with FC had a statistically significant higher score of family income/month as compared to other constipation subtype $(P=0.0112)$. Higher proportion of patients in both subtypes belonged to upper middle class (Table 1).

\section{Stool consistency}

The results of stool consistency were in concordance to the predefined definition of FC and IBS-C Bristol stool form types I, II and III. However, about $10 \%$ of FC and $19.5 \%$ of IBS-C patients also have reported stool form types VI and VII (Table 2).

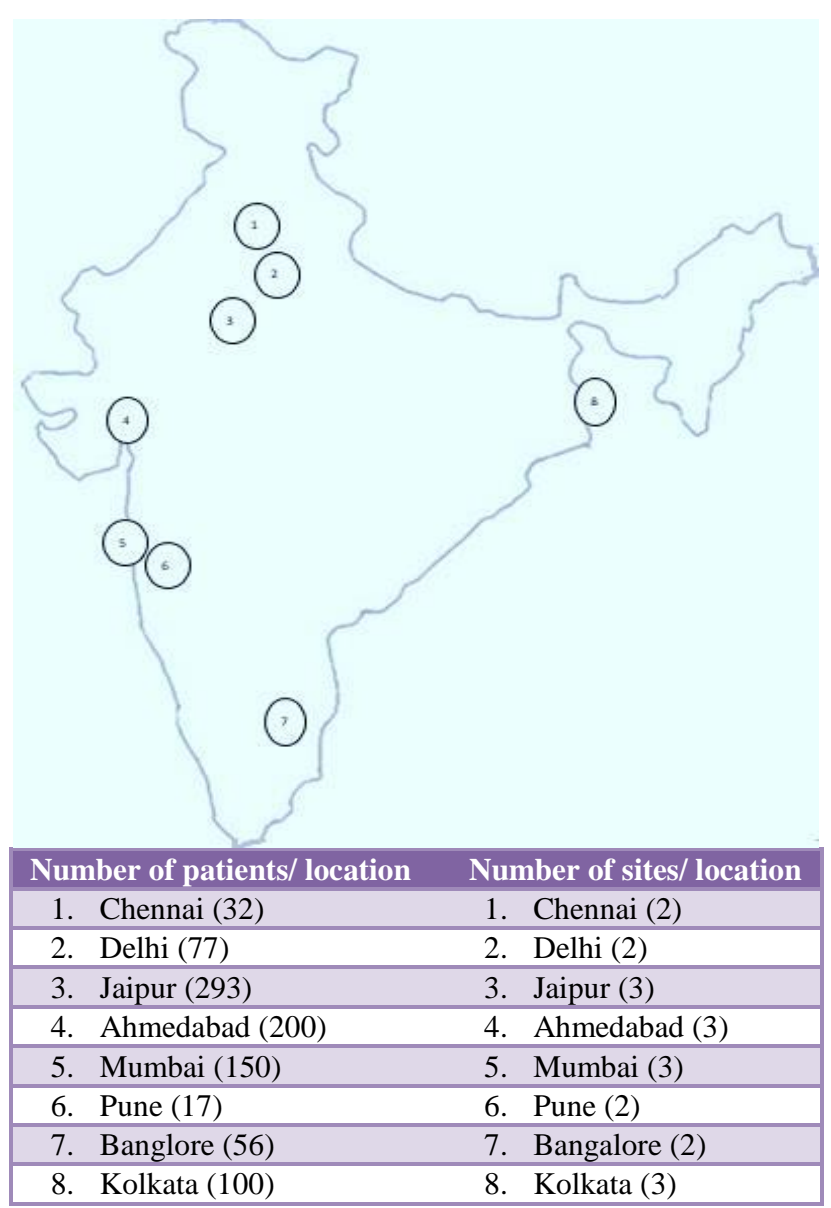

Figure 1: Distribution of sites and patient disposition.

Table 1: Socioeconomic classes.

\begin{tabular}{|c|c|c|c|}
\hline \multirow{2}{*}{ Class } & \multicolumn{2}{|c|}{ Types of Constipation } & \multirow[b]{2}{*}{ P-value } \\
\hline & FC $(n=699)$ & IBS-C (n = 226) & \\
\hline Education $[A]$, mean \pm SD & $4.3 \pm 1.8$ & $4.7 \pm 1.6$ & ${ }^{\mathrm{a}} 0.0026$ \\
\hline Occupation $[B]$, mean \pm SD & $3.6 \pm 3.1$ & $4.4 \pm 3.5$ & ${ }^{\mathrm{a}} 0.0031$ \\
\hline Family income [in Rs, 2014]/month $[C]$, mean \pm SD & $7.9 \pm 3.8$ & $7.1 \pm 3.6$ & ${ }^{\mathrm{a}} 0.0112$ \\
\hline Total score $[A+B+C]$, mean \pm SD & $15.7 \pm 6.9$ & $16.2 \pm 7.0$ & 0.3875 \\
\hline \multicolumn{4}{|l|}{ Socio-economic class, n (\%) } \\
\hline Upper $(\mathbf{i})=26-29$ & $96(13.7)$ & $41(18.1)$ & \\
\hline Upper middle (ii) $=\mathbf{1 6}-25$ & $250(35.8)$ & $76(33.6)$ & \\
\hline Lower middle $($ iii $)=11-15$ & $166(23.8)$ & $47(20.8)$ & \\
\hline Upper lower (iv) = 5-10 & $171(24.5)$ & $62(27.4)$ & \\
\hline Lower $(v) \leq 5$ & $16(2.3)$ & 0 & \\
\hline
\end{tabular}

${ }^{a}$ Significant

\section{Symptoms related to constipation}

The composite PAC-SYM score was high in both constipation subtypes but was statistically significantly higher in IBS-C patients $(30.1 \pm 4.9$ versus $27.1 \pm 6.0 ; P$ $<0.0001)$. Higher proportion of FC patients reported 'very severe' feeling of 'wanting to pass a bowel movement but couldn't' as compared to patients with IBS-C (5.72\% versus $0.88 \%)$.
Table 2: Stool consistency.

\begin{tabular}{|lll|}
\hline Type & $\begin{array}{l}\text { FC } \\
\mathbf{n = 6 9 9 ,} \mathbf{n}(\%)\end{array}$ & $\begin{array}{l}\text { IBS-C } \\
\mathbf{n = 2 2 6}, \mathbf{n}(\boldsymbol{\%})\end{array}$ \\
\hline I & $69(9.9)$ & $23(10.2)$ \\
\hline II & $148(21.2)$ & $41(18.1)$ \\
\hline III & $235(33.6)$ & $49(21.7)$ \\
\hline IV & $128(18.3)$ & $41(18.1)$ \\
\hline V & $47(6.7)$ & $28(12.4)$ \\
\hline VI & $47(6.7)$ & $31(13.7)$ \\
\hline VII & $25(3.6)$ & $13(5.8)$ \\
\hline
\end{tabular}


Table 3: Clinical parameters.

\begin{tabular}{|c|c|c|c|}
\hline Class & $\mathrm{FC}(\mathrm{n}=699)$ & IBS-C $(n=226)$ & P-value \\
\hline \multicolumn{4}{|l|}{ Patient Assessment of Constipation Symptoms (mean \pm SD) } \\
\hline Discomfort in your abdomen & $2.3 \pm 1.0$ & $2.5 \pm 1.0$ & ${ }^{\mathrm{a}} 0.0110$ \\
\hline Pain in your abdomen & $1.7 \pm 0.8$ & $2.4 \pm 0.8$ & ${ }^{\mathrm{a}}<0.0001$ \\
\hline Bloating in your abdomen & $2.5 \pm 1.1$ & $2.6 \pm 1.1$ & 0.0726 \\
\hline Stomach cramps & $1.5 \pm 0.8$ & $1.8 \pm 0.9$ & ${ }^{\mathrm{a}} 0.0002$ \\
\hline Painful bowel movements & $1.8 \pm 0.9$ & $1.9 \pm 1.0$ & ${ }^{\mathrm{a}} 0.0423$ \\
\hline Rectal burning during or after a bowel movement & $1.6 \pm 0.8$ & $1.7 \pm 0.9$ & 0.0711 \\
\hline Rectal bleeding or tearing during or after a bowel movement & $1.2 \pm 0.5$ & $1.2 \pm 0.5$ & 0.0688 \\
\hline Incomplete bowel movement, like you didn't "finish" & $3.2 \pm 1.2$ & $3.5 \pm 0.9$ & ${ }^{\mathrm{a}} 0.0002$ \\
\hline Bowel movements that were too hard & $3.0 \pm 1.0$ & $3.3 \pm 1.0$ & ${ }^{\mathrm{a}} 0.0009$ \\
\hline Bowel movements that were too small & $2.7 \pm 1.2$ & $3.3 \pm 0.9$ & ${ }^{\mathrm{a}}<0.0001$ \\
\hline Straining or squeezing to try to pass bowel movements & $3.2 \pm 1.2$ & $3.7 \pm 1.1$ & ${ }^{\mathrm{a}}<0.0001$ \\
\hline Feeling like you had to pass a bowel movement but you couldn't (false alarm) & $2.5 \pm 1.2$ & $2.2 \pm 1.2$ & ${ }^{\mathrm{a}} 0.0067$ \\
\hline Composite mean score of PAC-SYM & $27.1 \pm 6.0$ & $30.1 \pm 4.9$ & ${ }^{a}<0.0001$ \\
\hline \multicolumn{4}{|l|}{ Patient Assessment of Constipation Quality of Life (mean \pm SD) } \\
\hline Have you felt bloated to the point of bursting? & $1.4 \pm 1.2$ & $1.6 \pm 1.1$ & ${ }^{\mathrm{a}} 0.0021$ \\
\hline Have you felt heavy because of your constipation? & $2.0 \pm 1.1$ & $2.1 \pm 1.0$ & 0.0519 \\
\hline Have you felt any physical discomfort? & $1.6 \pm 1.1$ & $1.9 \pm 1.0$ & ${ }^{\mathrm{a}}<0.0001$ \\
\hline Have you felt the need to open your bowel but not been able to? & $1.6 \pm 1.2$ & $1.8 \pm 1.1$ & ${ }^{\mathrm{a}} 0.0120$ \\
\hline Have you been embarrassed to be with other people? & $0.9 \pm 1.1$ & $1.2 \pm 1.0$ & ${ }^{\mathrm{a}} 0.0021$ \\
\hline Have you been eating less and less because of not being able to have bowel movements? & $1.5 \pm 1.2$ & $1.7 \pm 1.2$ & ${ }^{\mathrm{a}} 0.0310$ \\
\hline Have you had to be careful about what you eat? & $1.4 \pm 1.2$ & $1.6 \pm 1.2$ & 0.1927 \\
\hline Have you had a decreased appetite? & $1.4 \pm 1.2$ & $1.5 \pm 1.3$ & 0.6799 \\
\hline $\begin{array}{l}\text { Have you been worried about not being able to choose what you eat (for example, at a } \\
\text { friend's)? }\end{array}$ & $1.0 \pm 1.1$ & $1.2 \pm 1.1$ & 0.0916 \\
\hline $\begin{array}{l}\text { Have you been embarrassed about staying in the toilet for so long when you were away } \\
\text { from home? }\end{array}$ & $1.0 \pm 1.0$ & $1.1 \pm 1.1$ & 0.1673 \\
\hline $\begin{array}{l}\text { Have you been embarrassed about having to go to the toilet so often when you were away } \\
\text { from home? }\end{array}$ & $1.0 \pm 1.0$ & $0.9 \pm 1.0$ & 0.9266 \\
\hline $\begin{array}{l}\text { Have you been worried about having to change your daily routine (for example, travelling, } \\
\text { being away from home)? }\end{array}$ & $1.2 \pm 1.1$ & $1.3 \pm 1.1$ & 0.1318 \\
\hline Have you felt irritable because of your condition? & $1.6 \pm 1.0$ & $1.8 \pm 0.9$ & ${ }^{\mathrm{a}} 0.0068$ \\
\hline Have you been upset by your condition? & $1.6 \pm 1.1$ & $1.8 \pm 1.0$ & ${ }^{\mathrm{a}} 0.0046$ \\
\hline Have you felt obsessed by your condition? & $1.3 \pm 1.2$ & $1.7 \pm 1.1$ & ${ }^{a}<0.0001$ \\
\hline Have you felt stressed by your condition? & $1.5 \pm 1.1$ & $1.8 \pm 1.0$ & ${ }^{\mathrm{a}}<0.0001$ \\
\hline Have you been less self-confident because of your condition? & $1.1 \pm 1.1$ & $1.7 \pm 1.0$ & ${ }^{\mathrm{a}}<0.0001$ \\
\hline Have you felt in control of your situation? & $1.8 \pm 1.2$ & $1.7 \pm 1.0$ & 0.5202 \\
\hline $\begin{array}{l}\text { Have you been worried about not knowing when you are going to be able to have a bowel } \\
\text { movement? }\end{array}$ & $1.4 \pm 1.0$ & $1.5 \pm 0.9$ & 0.2768 \\
\hline Have you been worried about not being able to open your bowels when you needed to? & $1.4 \pm 1.1$ & $1.6 \pm 1.1$ & 0.0982 \\
\hline Have you been more and more bothered by not being able to open your bowels? & $1.4 \pm 1.1$ & $1.7 \pm 1.0$ & ${ }^{\mathrm{a}} 0.0010$ \\
\hline Have you been afraid that your condition will get worse? & $1.5 \pm 1.0$ & $1.6 \pm 0.9$ & 0.1261 \\
\hline Have you been felt that your body was not working properly? & $1.5 \pm 1.0$ & $1.8 \pm 1.0$ & ${ }^{\mathrm{a}} 0.0003$ \\
\hline Have you had fewer bowel movements than you would like? & $1.9 \pm 1.1$ & $2.1 \pm 1.1$ & ${ }^{\mathrm{a}} 0.0108$ \\
\hline Have you been satisfied with how often you open your bowels? & $1.0 \pm 0.8$ & $0.8 \pm 0.8$ & ${ }^{\mathrm{a}} 0.0042$ \\
\hline Have you been satisfied with the regularity with which you open your bowels? & $0.9 \pm 0.9$ & $0.7 \pm 0.8$ & ${ }^{\mathrm{a}} 0.0007$ \\
\hline Have you been satisfied with your bowel function? & $0.9 \pm 0.9$ & $0.6 \pm 0.8$ & ${ }^{\mathrm{a}}<0.0001$ \\
\hline Have you been satisfied with your treatment? & $1.4 \pm 1.0$ & $1.5 \pm 1.0$ & 0.1389 \\
\hline Composite score based on PAC-QOL questionnaire & $38.1 \pm 16.8$ & $42.2 \pm 13.6$ & ${ }^{\mathrm{a}} 0.0002$ \\
\hline \multicolumn{4}{|l|}{ Constipation Scoring System $($ mean \pm SD) } \\
\hline Frequency of bowel movements & $0.1 \pm 0.3$ & $0.1 \pm 0.3$ & 0.6535 \\
\hline Difficulty: painful evacuation effort & $1.0 \pm 1.1$ & $1.4 \pm 1.4$ & ${ }^{\mathrm{a}} 0.0003$ \\
\hline Completeness: feeling incomplete evacuation & $2.7 \pm 1.3$ & $3.1 \pm 1.1$ & ${ }^{\mathrm{a}}<0.0001$ \\
\hline Pain: Abdominal pain & $0.9 \pm 1.0$ & $2.4 \pm 1.4$ & ${ }^{a}<0.0001$ \\
\hline Time: minutes in lavatory per attempt & $1.6 \pm 0.8$ & $1.6 \pm 0.9$ & 0.7884 \\
\hline Assistance: type of assistance & $0.4 \pm 0.5$ & $0.4 \pm 0.5$ & ${ }^{\mathrm{a}} 0.0273$ \\
\hline Failure: unsuccessful attempts for evacuation per 24 hours & $0.6 \pm 0.6$ & $0.5 \pm 0.6$ & ${ }^{\mathrm{a}} 0.0246$ \\
\hline History: duration of constipation (years) & $1.2 \pm 0.9$ & $1.6 \pm 1.1$ & ${ }^{\mathrm{a}}<0.0001$ \\
\hline Total mean CSS score & $8.4 \pm 3.1$ & $11.2 \pm 3.0$ & ${ }^{\mathrm{a}}<0.0001$ \\
\hline
\end{tabular}

${ }^{\mathrm{a}}$ Significant 
Similarly, a higher proportion of FC patients reported 'very severe' 'incomplete bowel movement of not being able to finish' (false alarm) as compared to IBS-C (14\% versus $8 \%$ ). IBS-C patients had statistically significant higher abdominal discomfort $(P=0.0110)$, pain in abdomen $(P<0.0001)$, stomach cramps $(P=0.0002)$, painful bowel movements $(P=0.0423)$, hard bowel movements $(P=0.0009)$, small bowel movements $(P$ $<0.0001)$ and straining/squeezing to try to pass bowel movements $(P<0.0001)$. Other symptoms like bloating in abdomen, painful bowel symptoms, rectal burning and rectal bleeding or tearing during or after a bowel movement were comparable between the constipation subtypes (Table 3).

\section{Quality of life}

The composite PAC-QoL score was high in both constipation subtypes but was statistically significantly higher in the IBS-C patients during 2 weeks prior to enrolment $(42.2 \pm 13.6$ versus $38.1 \pm 16.8$; difference: 4.13; $P=0.0002)$. Higher proportion of FC patients demonstrated embarrassment (47\% versus $27 \%)$, stress (22\% versus $11 \%)$, obsession (32\% versus $17 \%)$ and feeling of less confidence ( $43 \%$ versus $17 \%$ ) "most of the time" as compared to patients with IBS-C. Patients with IBS-C, against FC, had lower bowel movements than they would have liked to have and a higher feeling of bloating to the point of bursting, the body is not working properly, any physical discomfort, to open the bowel but not been able to do, feeling of eating less and less due to inability to have bowel movements, irritation, getting upset and high botheration due to inability to open the bowels. They had lower satisfaction regarding bowel movements and its regularity (Table 3 ).

\section{Severity of constipation}

The severity of constipation was high in both subtypes but a statistically significant higher total CSS score was reported in IBS-C patients than FC patients $(11.2 \pm 3$ versus $8.4 \pm 3.1 ; P<0.0001)$ These patients had a statistically significant higher abdominal pain ( $P$ $<0.0001)$, painful evacuation effort $(P=0.0003)$, feeling of incomplete evacuation $(P<0.0001)$, required assistance $(P=0.0273)$, and had a higher duration of constipation $(P<0.0001)$. The frequency of bowel movements and minutes in lavatory per attempt was comparable between the subtypes (Table 3). There was a statistically significant effect of QoL score on CSS score $(P<0.0001)$. However, there was no significant effect of age, gender, body mass index (BMI), dietary habits on CSS score.

\section{Lifestyle and dietary habits}

A statistically significant higher proportion of patients in both constipation subtypes had moderate physical activity, squatting position during defecation, were tea intakers, non-smokers, coffee and alcohol non-intakers $(P<0.0001)$. The median time needed for sensation of satisfactory bowel emptying while the patients sat on toilet seat/squatted was comparable between the constipation subtypes. Patients with FC against IBS-C had statistically significant higher protein/animal protein intake (grams per day) $(P<0.0001)$ while water, fruit and vegetable intake per day was comparable between the subtypes. Similar results were reported when the data was categorized by gender (Table 4).

\section{Concomitant medications}

Out of 925 patients enrolled, 549 (59.4\%) patients (FC: $56.7 \%$; IBS-C: $67.7 \%$ ) had used at least 1 medication for constipation-related symptoms. In FC patients, 36.6\%, $17.5 \%, 9.7 \%$ and $7.2 \%$ were on laxatives, antihypertensives, antidiabetics and antidepressants respectively. $50.9 \%, 40.7 \%$ and $14.2 \%$ patients with IBS$\mathrm{C}$ were on laxatives, drugs for acid related disorders and antihypertensives respectively (Table 5). The commonest laxatives used were osmotic and bulk laxatives in both types, however about $1 / 5^{\text {th }}$ patients of FC were on home remedies in the form of ayurvedic preparations (Figure 2).

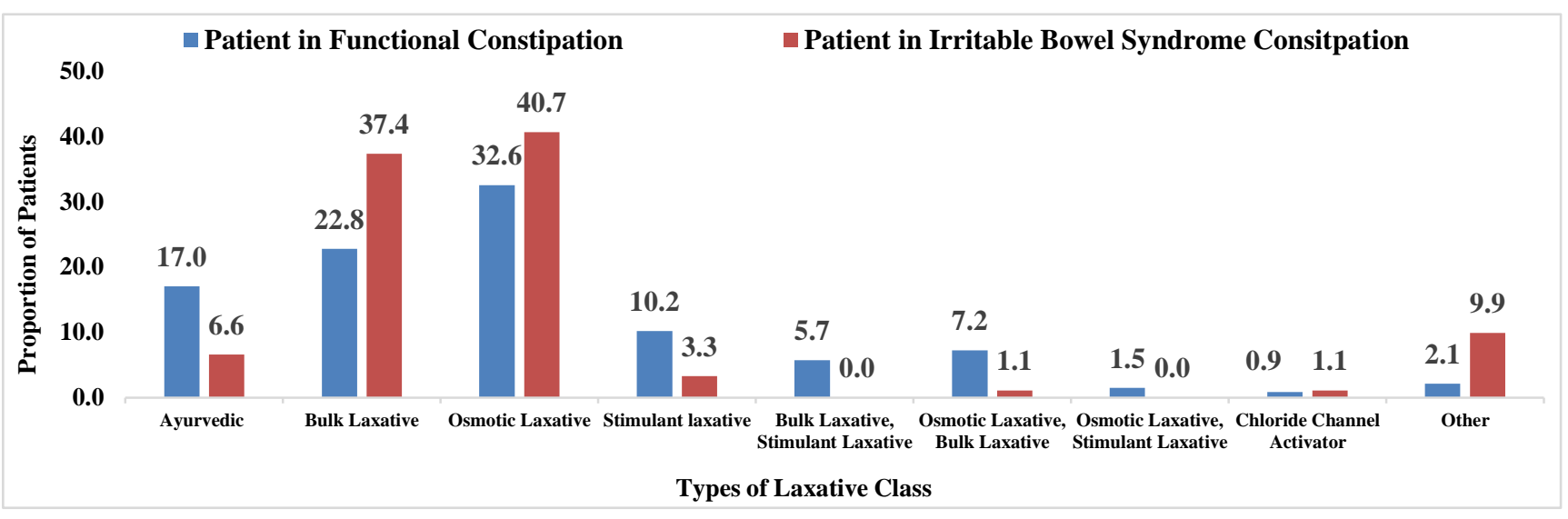

Figure 2: Types of laxatives. 
Table 4: Lifestyle and dietary habits.

\begin{tabular}{|c|c|c|c|}
\hline Class & $\mathrm{FC}(\mathrm{n}=699)$ & IBS-C $(n=226)$ & P-value \\
\hline \multicolumn{4}{|l|}{ Lifestyle Habits } \\
\hline Physical activity, $\mathrm{n}(\%)$ & & & ${ }^{\mathrm{a}}<0.0001$ \\
\hline Extremely active & $51(7.3)$ & $10(4.4)$ & \\
\hline Vigorously active & $92(13.2)$ & $35(15.5)$ & \\
\hline Moderately active & $378(54.1)$ & $133(58.9)$ & \\
\hline Sedentary & $144(20.6)$ & $43(19.0)$ & \\
\hline Extremely inactive & $34(4.9)$ & $5(2.2)$ & \\
\hline Posture during defecation (most frequent), $\mathrm{n}(\%)$ & & & ${ }^{\mathrm{a}}<0.0001$ \\
\hline Sitting on toilet seats & $231(33.1)$ & $57(25.2)$ & \\
\hline Squatting position & $468(67.0)$ & $169(74.8)$ & \\
\hline \multicolumn{4}{|l|}{ Time needed (in minutes) for } \\
\hline $\mathrm{N}$ & 699 & 226 & 0.9231 \\
\hline Mean (SD) & $14.2(9.0)$ & $14.3(9.8)$ & \\
\hline Median; Range & $12.0 ; 2: 9$ & $10.0 ; 2: 60$ & \\
\hline \multicolumn{4}{|l|}{ Smoking, n (\%) } \\
\hline Yes & $85(12.2)$ & $27(12.0)$ & ${ }^{\mathrm{a}}<0.0001$ \\
\hline No & $614(87.8)$ & $199(88.1)$ & \\
\hline \multicolumn{4}{|l|}{ Tea intake, n (\%) } \\
\hline Yes & $562(80.4)$ & $174(77.0)$ & ${ }^{\mathrm{a}}<0.0001$ \\
\hline No & $137(19.6)$ & $52(23.0)$ & \\
\hline \multicolumn{4}{|l|}{ Coffee intake, n (\%) } \\
\hline Yes & $64(9.2)$ & $14(6.2)$ & ${ }^{\mathrm{a}}<0.0001$ \\
\hline No & $635(90.8)$ & $212(93.8)$ & \\
\hline \multicolumn{4}{|l|}{ Alcohol intake, n (\%) } \\
\hline Yes & $51(7.3)$ & $11(4.87)$ & ${ }^{\mathrm{a}}<0.0001$ \\
\hline No & $638(91.3)$ & $207(91.6)$ & \\
\hline Stopped & $10(1.4)$ & $8(3.5)$ & \\
\hline \multicolumn{4}{|l|}{ Dietary Habits } \\
\hline Water intake (litres/day) & & & 0.5455 \\
\hline $\mathrm{N}$ & 673 & 187 & \\
\hline Mean (SD) & $2.5(1.4)$ & $2.6(1.7)$ & \\
\hline Median; Range & $2.0 ; 0: 2$ & $2.0 ; 1: 10$ & \\
\hline Fruits intake (gm/day) & & & 0.4050 \\
\hline $\mathrm{N}$ & 697 & 224 & \\
\hline Mean (SD) & $107.0(110.8)$ & $114.0(100.8)$ & \\
\hline Median; Range & $100.0 ; 0: 9$ & $100.0 ; 0: 6$ & \\
\hline Vegetable intake (gm/day) & & & 0.8082 \\
\hline $\mathrm{N}$ & 699 & 226 & \\
\hline Mean (SD) & $227.1(123.9)$ & $224.8(112.8)$ & \\
\hline Median; Range & $200.0 ; 0: 8$ & $200.0 ; 2: 9$ & \\
\hline Protein/Animal Protein intake (gm/day) & & & ${ }^{\mathrm{a}}<0.0001$ \\
\hline $\mathrm{N}$ & 698 & 225 & \\
\hline Mean (SD) & $47.9(27.5)$ & $39.1(25.7)$ & \\
\hline Median; Range & $42.0 ; 0: 3$ & $35.0 ; 0: 2$ & \\
\hline
\end{tabular}

${ }^{\mathrm{a} S i g n i f i c a n t}$

\section{Co-morbid conditions}

Overall, 321 patients $(34.7 \%)$ with constipation had a history of at least one medical condition. Hypertension (16\%), diabetes $(10 \%)$ and GI disorders $(8.3 \%)$ were the most common comorbidities in FC patients while acid peptic disorders $(21.7 \%)$, hypertension $(13.7 \%)$ were the most common comorbidities in IBS-C patients. 
Table 5: Concomitant medications.

\begin{tabular}{|ll|l|}
\hline Concomitant Medications & $\begin{array}{l}\text { FC } \\
(\mathbf{n = 6 9 9 )} \\
\mathbf{n}(\%)\end{array}$ & $\begin{array}{l}\text { IBS-C } \\
(\mathbf{n = 2 2 6 )} \\
\mathbf{n}(\%)\end{array}$ \\
\hline $\begin{array}{l}\text { Number of patients has } \\
\text { taken at least one } \\
\text { concomitant medication }\end{array}$ & $396(56.7)$ & $153(67.7)$ \\
\hline Laxatives & $256(36.6)$ & $115(50.9)$ \\
\hline $\begin{array}{l}\text { Drugs for acid related } \\
\text { disorders }\end{array}$ & $142(20.3)$ & $92(40.7)$ \\
\hline Antihypertensives & $122(17.5)$ & $32(14.2)$ \\
\hline Drug used in diabetes & $68(9.7)$ & $11(4.9)$ \\
\hline Antidepressants & $50(7.2)$ & $16(7.1)$ \\
\hline Serum lipid reducing agents & $53(7.6)$ & $9(4.0)$ \\
\hline Analgesics & $21(3.0)$ & $28(12.4)$ \\
\hline Thyroid Hormones & $21(3.0)$ & $9(4.0)$ \\
\hline
\end{tabular}

\section{DISCUSSION}

There is a lack of robust Indian data on the community population suffering from constipation. The true prevalence of FC and IBS is difficult to estimate as it is known to change depending on the criteria used for diagnosis. In 1992, Rome criteria was laid down to bring out uniformity in diagnosis of GI disorders which was further modified in 1999 and 2006. ${ }^{11,12}$ Constipation is best defined using the Rome III criteria and is universally accepted in clinical trials and epidemiological studies. Ours is the first pan-India study, which assessed the prevalence of FC and IBS-C amongst 925 patients with an established diagnosis of constipation across different geographical locations of India. In the present study, the prevalence of FC was higher than IBS-C $(75.6 \%$ versus $24.4 \%$ patients) in constipated Indian population. Our results were similar to the recently published US population-based survey where the symptoms, care seeking, and disease burden of IBS-C and FC were evaluated in patients diagnosed with IBS-C and FC as per Rome III criteria; $62.7 \%$ patients were diagnosed with FC and $37.3 \%$ with IBS-C. ${ }^{13}$ The prevalence of FC and IBS$\mathrm{C}$ in our study was remarkably higher than the earlier reported Indian and Western literature due to the reason that we have evaluated the subtypes in already diagnosed constipated patients unlike the reported literature which have assessed the prevalence of constipation subtypes in the community/general population. In 2013, Kasthuri et al. reported the prevalence of FC as $8.7 \%$ among elderly population (aged 60 to $>80$ years) in a cross-sectional community based study. ${ }^{14}$ In 2011, Suares and Ford reported the pooled prevalence of FC from 41 separate study populations as $14 \%$ (95\% CI:12-17\%). ${ }^{7}$ Similar results were reported in other studies where the prevalence of FC varied from $2.6 \%$ to $30.7 \%$ of the general population. ${ }^{8,15,16}$ The dichotomy in the data is due to the reason that in our study, the subtypes of constipation in already diagnosed constipated patients has been studied, unlike reported literature which has assessed the prevalence of constipation subtypes in the community at large. Various population-based studies estimated the prevalence of IBS in India and Western countries as $4.2-7.9 \%$ and $10-20 \%$, respectively. ${ }^{10}$ In 2011, Makharia et al. estimated the prevalence of IBS in a rural community in Ballabgarh block, Haryana, India as $4 \%(191 / 4767$ subjects) and $6.3 \%$ of these patients had IBS-C. ${ }^{17}$

The average age of FC patients was significantly higher than of IBS-C patients. Both Indian and Western studies have reported a higher prevalence of IBS in young followed by a decline with increasing age. ${ }^{10,18}$ In our study, the higher proportion of patients with both subtypes had urban residence; this may be due to the reason that patients staying in the urban areas are more prone to a sedentary lifestyle, have a higher frequency of eating junk food, lead more stressful lives, have a higher frequency of comorbidities leading to high consumption of medications; which further results in altered bowel function and an increased likelihood of constipation. It is important to note that our study was largely based on the urban Indian population.

In our study, there was a higher proportion of males against females (about 2:1) in both constipation subtypes. Similar results were reported earlier where the prevalence of IBS was found to be higher in males over females. ${ }^{10,19}$ However, various studies in Western countries have reported clinical symptoms of IBS in higher proportion of females compared to males $(2: 1) .{ }^{19}$ It is important to note that more males participated in this study which could have had a possible influence on the male:female representation in the study.

The major causes of constipation are increased BMI (due to release of pro-inflammatory cytokines), altered lifestyle and dietary habits, including poor fibre diet, inadequate water and juice intake, high caffeine and alcohol intake (have a dehydrating effect), physical inactivity, laxative abuse, sedentary lifestyle, various diseases like diabetes, hypothyroidism, hypercalcemia, hypokalemia, medications-antacids, antidepressants, calcium channel blockers, iron supplements, diuretics etc. ${ }^{1}$ In our study, the higher proportion of patients with both subtypes had the habit of taking tea (FC: $80.4 \%$; IBS-C: $77 \%$ ). The results were in concordance to the previous literature where constipated individuals were reported to have a higher consumption of tea. The study also reported that the effect of tea on constipation is probably due to theophylline, which acts as a diuretic and causes extracellular dehydration with a secondary increase in intestinal fluid absorption, thereby leading to constipation. $^{20}$ In the present study, there were no significant differences in BMI, tea or coffee consumption, alcohol intake or smoking status between the constipation subtypes. Our results were in agreement to the previous cross-sectional survey conducted in adult Chinese population ( $\mathrm{n}=16$ 078) where BMI, alcohol consumption, and smoking status were comparable across both constipation subtypes. ${ }^{21}$ In 2008, Pourhoseingholi et 
al. conducted a cross-sectional study in Tehran province where $40 \%$ of FC patients were overweight and $20 \%$ were obese, indicating a clear association between obesity and FC; however Zhao et al, in 2011 found a negative correlation between high BMI and FC and few studies reported no significant relationship between BMI and FC. ${ }^{22-24}$ In 2013, Farzaneh et al. evaluated the effects of demographic factors, BMI, alcohol drinking and smoking habits in 153 IBS patients against 163 non-IBS patients at Taleghani Hospital Gastroenterology Clinic at Tehran. The authors found no association between BMI and IBS in males but a significant association was seen among BMI <25 and female gender. In addition, no association was reported between alcohol and smoking habits in IBS and non-IBS patients ${ }^{25}$. In a study on 1978 individuals over 35 years in Shiraz, southern Iran, Khademolhosseini, et al. found no association between IBS and BMI and Liu et al. in 2006 also reported no association between FC and alcohol consumption and smoking status. ${ }^{26,27}$

Socioeconomic characteristics are an important determinant of health, nutritional status, mortality and morbidity and influence the accessibility, affordability, acceptability, and actual utilization of the available health facilities. ${ }^{28,29}$ The Kuppuswamy scale is commonly used to determine the socioeconomic status of an individual based on the overall score of education, occupation of the head of the family and family income per month. ${ }^{28}$ Though, constipation has been reported to be inversely related to socioeconomic status, in our study the patients with upper middle class had a higher prevalence of constipation subtypes; which may be due to lack of physical activity, consumption of low-fiber diet, inadequate water intake, co-morbidities and higher use of medications. $^{29}$

We have used BSFS in our study to identify the stool consistency. The recording of the findings of stool consistency were based on the recall by the patients. Our study results were in concordance to the predefined definition of FC and IBS-C having stool form types I, II and III. However, about $10 \%$ of FC and $19.5 \%$ of IBS-C patients also have reported stool form types VI and VII. This finding may be largely attributed to the fact that readings were based on patient recall, one point observation and possibility of on going laxative therapy to the patients.

PAC-SYM, a 12-item self-report questionnaire, is a reliable, valid and responsive measure of the presence and severity of constipation-related symptoms. ${ }^{30}$ The composite mean score of PAC-SYM along with other domains was high in both subtypes but was significantly higher in IBS-C compared to FC patients. Our results were analogous to a previously US population-based survey where the frequency of each of abdominal and bowel symptoms were significantly higher in patients with IBS-C against FC. ${ }^{13}$ In 2011 , Zhao et al. reported 'the feeling of straining during a bowel movement' to be statistically significantly higher in FC patients against IBS-C (75\% versus $65 \% ; P=0.005)$ and 'the feeling of incomplete evacuation after bowel movement' to be statistically significantly higher in IBS-C compared to FC patients $(38 \%$ versus $31 \%, P=0.045)$. Other symptoms of constipation were comparable between both constipation subtypes. $^{21}$

The severity of constipation was assessed by CSS. Patients of both constipation subtypes had a high severity of constipation and about $50 \%$ of patients with FC spent $>10$ minutes in the lavatory per attempt. However, the total CSS score was significantly higher in patients with IBS-C compared to FC.

Various studies have reported that patients with chronic constipation have a lower QoL with higher job absenteeism and lower work productivity, regardless of culture/nationality. ${ }^{4,16,31}$ In 2011, Sun et al. compared the QoL of constipated patients versus non-constipated patients and reported that constipated patients have a significantly lower QoL than the control group. ${ }^{3}$ Belsey et al., in a meta-analysis of QoL in chronic constipation, reported that FC patients had a lower QoL in all areas of evaluation when compared to healthy controls. ${ }^{32}$ In our study as well, patients with FC had a high PAC-QoL score, signifying poor QoL. Because of the impact on QoL, higher proportion of FC patients were 'embarrassed' (47\% versus 27\%), 'stressed' (22\% versus $11 \%)$, 'obsessed' (32\% versus 17\%) and 'felt less confident' (43\% versus 17\%) "most of the time" as compared to IBS-C patients. However, patients with IBS$\mathrm{C}$ had significantly higher frequency and severity of constipation (higher composite PAC-QoL score) than FC patients. Our results were in concordance to the earlier reported literature wherein patients with IBS-C demonstrated higher PAC-QoL score than patients with $\mathrm{FC}^{33}$. In another study, similar results were observed where patients with IBS-C were significantly more bothersome to abdominal discomfort, bloating, straining, pellet like stools and constipation than FC patients with abdominal symptoms. ${ }^{13}$

The management of constipation has a multi-faceted approach. Once the diagnosis of constipation is established, it is important to counsel the patients on adequate dietary fiber, fluid intake, and lifestyle modifications as they are an integral part of the initial conservative management. Fiber supplementation can be added, if necessary. If constipation is not adequately managed, then the other laxatives like osmotic/stimulant can be added. ${ }^{8,34}$ In our study, laxative was the most common concomitant medication used in both constipation subtypes (FC: $36.6 \%$; IBS-C: $50.9 \%$ ). Of these laxatives, osmotic and bulk laxatives were the most common laxatives used by patients of both constipation subtypes. The study results were in concordance to the previously published literature where osmotic and bulk laxatives were used in relieving the constipation-related symptoms in patients with IBS-C and FC. ${ }^{35,36}$ However, 
the point to highlight here is that, only $36.6 \%$ patients of FC and $50.9 \%$ patients of IBS-C were on laxative therapy. Moreover, about $1 / 5^{\text {th }}$ patients of FC were using home remedies for the same. This indicates the importance of appropriate and relevant pharmacotherapy for overall symptomatic relief of constipation with improved QoL.

Patients suffering from comorbid conditions like diabetes, hypothyroidism, hypertension and cardiovascular, neurological, GI and other metabolic disorders frequently experience constipation due to disordered colonic and/or pelvic floor/anorectal function $^{37}$. In the present study, higher proportion of FC patients had a history of hypertension (16\%) and diabetes $(10.2 \%)$; resulting in higher utilization of antihypertensive and antidiabetic medications, further leading to lower frequency of bowel movements. Previous studies have reported the prevalence of constipation as $15 \%$ in diabetic patients, mainly because of autonomic neuropathy affecting colonic motility ${ }^{38}$. About $28 \%$ of the IBS-C patients had the history of GI disorders (dyspepsia and acid peptic disease), due to higher visceral hypersensitivity and GI motility, which led to irregular bowel habits. Numerically, a higher proportion of IBS-C patients were on drugs for acidrelated disorders compared to FC patients (40.7\% versus $20.3 \%$ ); these medications further exacerbated the severity of constipation-related symptoms. Our results were comparable to a previously reported literature where patients with IBS-C were much more likely to report gastroesophageal reflux disorder. ${ }^{21,39}$ In another study, dyspepsia and diabetes were reported as the most common comorbidities in patients with IBS-C and FC, respectively. ${ }^{37}$ In addition, $7.15 \%$ patients of $\mathrm{FC}$ were on antidepressants for management of stress/ anxiety/ depression. Literature review reports that anxiety/depression is the independent risk factors for constipation. $^{1,40}$ Moreover, our study demonstrates that medications used for treatment of anxiety/depression can also cause constipation as side effect.

Our study has several strengths. First, it was a first of its kind pan India study including both rural and urban population based on diverse and categorized parameters (socioeconomic, lifestyle, and dietary habits) which helped to analyze different parameters across different geographical location of India. Second, patients of varying age were evaluated which gave higher flexibility to include patients of both subtypes of constipation. Third, all the parameters, including consistency of stool, constipation related symptoms, severity of symptoms and QoL has been assessed by very well-defined, validated and reliable tools. Fourth, there was a great association between the entire questionnaires used which provided a refined and well detailed data about a particular study variable. Fifth, all the questionnaires used in the study were administered to the patients by a physician or a designee, which enabled to capture information with greater accuracy and confidentiality. Sixth, the study provided valuable data which could be used to increase the epidemiological understanding of both FC and IBS-C in Indian population. The study has several limitations. First, this study was only limited to adult population and has not been studied in children and elderly population. Second, it was a single visit study and lacked long-term outcome data. Third, it is a non-interventional study; hence no data was collected regarding the effect of changes in the management.

\section{CONCLUSION}

In conclusion, this study demonstrates the high prevalence of FC in the Indian population. Patients with both constipation subtypes had a high frequency and severity of symptoms related to constipation (high PACSYM and CSS score), thereby leading to impairment of their QoL (high PAC-QoL score). Higher proportion of FC patients had a history of hypertension and diabetes which resulted in higher utilization of antihypertensive and anti-diabetic medications, whereas higher proportion of patients with IBS-C had a history of gastrointestinal disorders (dyspepsia and acid peptic disease). Thus, it is very important to identify patients of constipation amongst relevant comorbidities, with use of concomitant medications. Though osmotic and bulk laxatives were the most commonly used laxatives in both constipation subtypes, yet a considerable proportion of patients were found to use home remedies for the same. Thus, there is a definite need to highlight importance of appropriate pharmacotherapy for effective constipation management and overall improvement in QoL.

\section{ACKNOWLEDGEMENTS}

The authors thank the study participants as well as the following investigators for their participation in this study (listed in alphabetical order): Dr. Ashwani Aggarwal, Dr. Umesh Aalegaonkar, Dr. Bhattacharya, Dr. Sanmay Choudhari, Debasis Datta, Dr. Kamlesh Fatania, Dr. Amit Goyal, Dr. Deepak Kumar Jha, Dr. Mandhir Kumar, Dr. Parimal Lawate, Dr. Mahesh Jagdish Maheshwari, Dr. Chetan Nayak, Dr. Sandeep Nijhawan, Dr. Swami Pawar, Dr. Ravindra BS, Dr. Shanthi V and Dr. Jayanthi. V. JSS Medical Research India Ltd assisted in the overall development of this manuscript.

Funding: Funding sources from Abbott India Ltd. Conflict of interest: Dr. Rooprai, Dr. Bhat and Dr. Sainani have received research funding from Abbott India. Ltd. Dr. Mayabhate is an employee of Abbott India Ltd.

Ethical approval: The study was approved by the Institutional Ethics Committee

\section{REFERENCES}

1. Jamshed N. Diagnostic Approach to Chronic Constipation in Adults. Am Fam Physician. 2011;84:299-306. 
2. Longstreth GF, Thompson WG, Chey WD, Houghton LA, Mearin F, Spiller RC. Functional bowel disorders. Gastroenterol. 2006;130:1480-91.

3. Sun SX, Dibonaventura M, Purayidathil FW, Wagner JS, Dabbous O, Mody R. Impact of chronic constipation on health-related quality of life, work productivity, and healthcare resource use: an analysis of the National Health and Wellness Survey. Dig Dis Sci. 2011;56:2688-95.

4. Gonzalez-Martinez MA, Ortiz-Olvera NX, MendezNavarro J. Novel pharmacological therapies for management of chronic constipation. J Clin Gastroenterol. 2014;48:21-8.

5. Remes Troche JM, Remes Troche JM, Tamayo de la Cuesta JL, Raña Garibay R, Huerta Iga F, Suarez Morán E, et al. Association Mexicana de Gastroenterología. [Guidelines for diagnosis and treatment of constipation in Mexico. A) Epidemiology (meta-analysis of the prevalence), pathophysiology and classification]. Rev Gastroenterol Mex. 2011;76:126-32.

6. Lopez CA, Rivera RJF, Sobrino CS, Suárez ME. [Gastroenterology diagnosis and treatment guidelines of irritable bowel syndrome; epidemiology and physiopathology]. Rev Gastroenterol Mex. 2009;74:56-7.

7. Suares NC, Ford AC. Prevalence of, and risk factors for, chronic idiopathic constipation in the community: systematic review and metaanalysis. Am J Gastroenterol. 2011;106:1582.

8. Bharucha AE, Dorn SD, Lembo A, Pressman A. American Gastroenterological Association medical position statement on constipation. Gastroenterology. 2013;144:211-7.

9. Chaud D, Olivon E, Machado A, Abreu E. Prevalence of functional constipation and its risk factors among university students (LB328). The FASEB Journal. 2014;28(1):LB328.

10. Upadhyay R, Singh A. Irritable Bowel Syndrome: The Indian Scenario. In Medicine Update. 2013. Available http://www.apiindia.org/medicine_update_2013/chap 56.pdf. Accessed 22 Sep 2016.

11. Chan AO, Lam KF, Hui WM, Hu WH, Li J, Lai KC, et al. Validated questionnaire on diagnosis and symptom severity for functional constipation in the Chinese population. Aliment Pharmacol Ther. 2005;22:483-8.

12. Drossman DA. The functional gastrointestinal disorders and the Rome III process. Gastroenterology. 2006;130:1377-90.

13. Heidelbaugh JJ, Stelwagon M, Miller SA, Shea EP, Chey WD. The spectrum of constipationpredominant irritable bowel syndrome and chronic idiopathic constipation: US survey assessing symptoms, care seeking, and disease burden. Am J Gastroenterol. 2015;110:580-7.

14. Kasthuri A, Hegde SKB, Joseph MA, Rao DP, Gomez G, Sahu A. Prevalence of constipation among elderly in a rural area of Bangalore. IJRRMS. 2013;3:9-11.

15. Tack J, Muller-Lissner S. Treatment of chronic constipation: Current pharmacologic approaches and future directions. Clin Gastroenterol Hepatol. 2009;7:502-8.

16. Pinto Sanchez MI, Bercik P. Epidemiology and burden of chronic constipation. Can J Gastroenterol. 2011;25:11B-5B.

17. Makharia GK, Verma AK, Amarchand R, Goswami A, Singh P, Agnihotri A, et al. Prevalence of irritable bowel syndrome: a community based study from northern India. J Neurogastroenterol Motil. 2011;17:82-7.

18. Talley NJ, Zinsmeister AR, Melton IJ 3rd. Irritable bowel syndrome in a community: symptoms subgroups, risk factors and a health care utilization. Am J Epidemiol. 1995;142:76-83.

19. Luo JC, Lin HY, Chang FY, Lu RH, Lu CL, Chen $\mathrm{CY}$, et al. Occurrence of peptic ulcer disease in connective tissue disease patients associated with xerostomia. Aliment Pharmacol Ther. 2003;17:21724.

20. Sandler RS, Jordan MC, Shelton BJ. Demographic and dietary determinants of constipation in the US population. Am J Public Health. 1990;80:185-9.

21. Zhao YF, Ma XQ, Wang R, Yan XY, Li ZS, Zou $\mathrm{DW}$, et al. Epidemiology of functional constipation and comparison with constipation-predominant irritable bowel syndrome: The Systematic Investigation of Gastrointestinal Diseases in China (SILC). Aliment Pharmacol Ther. 2011;34:1020-9.

22. Pourhoseingholi MA, Kaboli SA, Pourhoseingholi A, Moghimi-Dehkordi B, Safaee A, Mansoori BK. Obesity and functional constipation; a communitybased study in Iran. J Gastrointestin Liver Dis. 2009;18:151-5.

23. Talley NJ, Quan C, Jones MP, Horowitz M. Association of upper and lower gastrointestinal tract symptoms with body mass index in an Australian cohort. Neurogastroenterol Motil. 2004;16:413-9.

24. Murakami K, Sasakii S, Okubo H, Takahashi Y, Hoso Y, Itabashi M. Freshmen in Dietetic Courses Study II Group. Food intake and functional constipation: a cross-sectional study of 3,835 Japanese women aged 18-20 years. J Nutr Sci Vitaminol (Tokyo). 2007;53:30-6.

25. Farzaneh N, Ghobaklou M, Moghimi-Dehkordi B, Naderi N, Fadai F. Effects of demographic factors, body mass index, alcohol drinking and smoking habits on irritable bowel syndrome: a case control study. Ann Med Health Sci Res. 2013;3:391-6.

26. Khademolhosseini F, Mehrabani D, Nejabat M, Beheshti M, Heydari ST, Mirahmadizadeh A, et al. Irritable bowel syndrome in adults over 35 years in Shiraz, southern Iran: Prevalence and associated factors. J Res Med Sci. 2011;16:200-6.

27. Lu CL, Chang FY, Chen CY, Luo JC, Lee SD, Significance of Rome II-defined functional constipation in Taiwan and comparison with 
constipation-predominant irritable bowel syndrome. Aliment Pharmacol Ther. 2006;24:429-38.

28. Gururaj, Maheshwaran. Kuppuswamy's socioeconomic status scale - a revision of income parameter for 2014. IJRTSAT. 2014;11:01-2.

29. Higgins PD, Johanson JF. Epidemiology of functional constipation in North America: a systematic review. Am J Gastroenterol. 2004;99:750-9.

30. Slappendel R, Simpson K, Dubois D, Keininger DL. Validation of the PAC-SYM questionnaire for opioid-induced constipation in patients with chronic low back pain. Eur J Pain. 2006;10:209-17.

31. Glia A, Lindberg G. Quality of life in patients with different types of functional constipation. Scand J Gastroenterol. 1997;32:1083-9.

32. Belsey J, Greenfield S, Candy D, Geraint $M$. Systematic review: impact of constipation on quality of life in adults and children. Aliment Pharmacol Ther. 2010;31:938-49.

33. Ruiz-López MC, Coss-Adame E. Calidad de vida en pacientes con diferentes subtipos de estre nimiento de acuerdo a los criterios de ROMA III. Revista de Gastroenterología de México. 2015;80:13-20.

34. Brandt LJ, Prather CM, Quigley EM, Schiller LR, Schoenfeld P, Talley NJ. Systematic review on the management of chronic constipation in North America. Am J Gastroenterol. 2005;100:S5-21.

35. Bijkerk CJ, de Wit NJ, Muris JW, Whorwell PJ, Knottnerus JA, Hoes AW. Soluble or insoluble fibre in irritable bowel syndrome in primary care? Randomised placebo controlled trial. BMJ. 2009;339:b3154.
36. Chapman RW, Stanghellini V, Geraint M, Halphen M. Randomized clinical trial: macrogol/PEG 3350 plus electrolytes for treatment of patients with constipation associated with irritable bowel syndrome. Am J Gastroenterol. 2013;108:1508-15.

37. Nellesen D, Chawla A, Oh DL, Weissman T, Lavins BJ, Murray CW. Comorbidities in patients with irritable bowel syndrome with constipation or chronic idiopathic constipation: a review of the literature from the past decade. Postgrad Med. 2013;125:40-50.

38. Oh JH, Choi MG, Kang MI, Lee KM, Kim JI, Kim $\mathrm{BW}$, et al. The prevalence of gastrointestinal symptoms in patients with non-insulin dependent diabetes mellitus. Korean J Intern Med. 2009;24:30917.

39. Yarandi SS, Nasseri-Moghaddam S, Mostajabi P, Malekzadeh R. Overlapping gastroesophageal reflux disease and irritable bowel syndrome: Increased dysfunctional symptoms. World J Gastroenterol. 2010;16:1232-8.

40. Hosseinzadeh ST, Poorsaadati S, Radkani B, Forootan M. Psychological disorders in patients with chronic constipation. Gastroenterol Hepatol Bed Bench Summer. 2011;4:159-63.

Cite this article as: Rooprai $\mathrm{R}$, Bhat $\mathrm{N}$, Sainani $\mathrm{R}$, Mayabhate MM. Prevalence of functional constipation and constipation-predominant irritable bowel syndrome in Indian patients with constipation. Int J Basic Clin Pharmacol 2017;6:275-85. 